\title{
Analytical and Experimental Investigations on Mechanical Properties of Weak Plane Bedding in Mudstone
}

\author{
Yijin Zeng, ${ }^{1}$ Hailong Jiang $\mathbb{D}^{1,2}$ Shidong Ding, Junhai Chen, ${ }^{1}$ Yi Wang, ${ }^{1}$ and Jie Zheng ${ }^{2}$ \\ ${ }^{1}$ State Key Laboratory of Shale Oil and Gas Enrichment Mechanisms and Effective Development, Beijing 100083, China \\ ${ }^{2}$ College of Mechanical Engineering, Xi'an Shiyou University, Xi'an, Shannxi 710065, China \\ Correspondence should be addressed to Hailong Jiang; jianghl_xapi@126.com
}

Received 19 April 2021; Accepted 22 May 2021; Published 4 June 2021

Academic Editor: Yu Wang

Copyright (C) 2021 Yijin Zeng et al. This is an open access article distributed under the Creative Commons Attribution License, which permits unrestricted use, distribution, and reproduction in any medium, provided the original work is properly cited.

\begin{abstract}
Wellbore instabilities frequently occur in mudstone formation with weak plane bedding because of strong anisotropies. The mechanics parameters of weak plane bedding are of vital significance to the wellbore stability analysis for mudstone formations. The conventional method for determining the mechanics parameters is to fit lots of triaxial test data due to the blindness of coring. In this paper, an evaluation method of the mechanics parameters of weak plane bedding is proposed to improve the accuracy of weak plane bedding mechanical properties. The mechanics parameters of weak plane bedding are obtained by combing the single-weak plane failure criterion with the compressive strength of rock obtained by the triaxial test of cores with different coring angles. It is seen that the new evaluation method is simple and convenient. On the other hand, a validation method of the mechanics parameters of weak plane bedding is proposed to ensure their accuracy. The compressive strength obtained from the core with the special coring angle is compared with the theoretical compressive strength for verifying the accuracy of weak plane bedding mechanical properties. It is observed that the proposed evaluation and validation methods can be used to measure the value of weak plane bedding mechanical properties precisely. The proposed methods are general and can be used for measuring the mechanical properties of fracture weak-plane and joint weak-plane.
\end{abstract}

\section{Introduction}

The anisotropic rock (mudstone, shale, etc.) formed by the weak plane (bedding, joint, etc.) can be weaker than the intact rock. The current research focuses on the failure criterion of the anisotropic rock, such as the Mohr-Coulomb, DruckerPrager, the Modified Lade, Hoek-Brown, single-weak plane failure criterion, and 3D criteria (Mogi-Coulomb, WiebolsCook, Desai-Salami, 3D Hoek-Brown) [1-4]. The 3D criteria focus on the effects of the intermediate principal stress, which is usually difficult in practice to analyze the wellbore stability because of the more required input parameters. One of the most widely used empirical criteria in the anisotropic rock is the single-weak plane failure criterion. Since its first introduction by Jaeger [2] in extending the earlier work of Bott [1], the single-weak plane failure criterion has been used successfully in evaluating wellbore stability [5-13]. In this criterion, the failure of both the bedding planes and rock matrix is described by using the Mohr-Coulomb criterion by two dif- ferent sets of intact rock and weak plan constants. Then, the mechanics parameters of weak plane bedding are important parameters required for use of the single-weak plane failure criterion in evaluation wellbore stability. The conventional method for determining the mechanics parameters is to fit lots of triaxial test data of anisotropic rocks [1419]. Donath [14] tested the several rocks with different types of planar anisotropy with seven different $\delta$, where $\delta$ is the inclination of anisotropy, bedding planes. Chenevert and Gatlin [15] early showed the rock properties of coefficient of internal friction can vary with direction, depending on the particular rock tested. Duveau and Shao [16] performed 78 triaxial compression tests in order to investigate the schist strength anisotropy. The cohesion and friction of weakness planes are determined from failure stresses obtained in triaxial tests with the loading orientation resulting in the minimum strength. Heng et al. [17] analyzed the mechanical properties of the bedding plane based on the experimental data of shale with four different $\alpha$, where $\alpha$ is the angle 


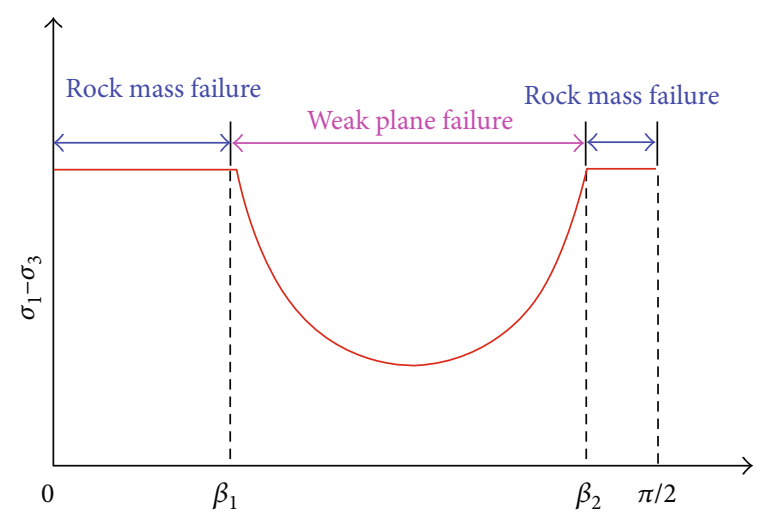

FIgURE 1: Relation between the failure mode of the anisotropic mudstone and $\beta$.

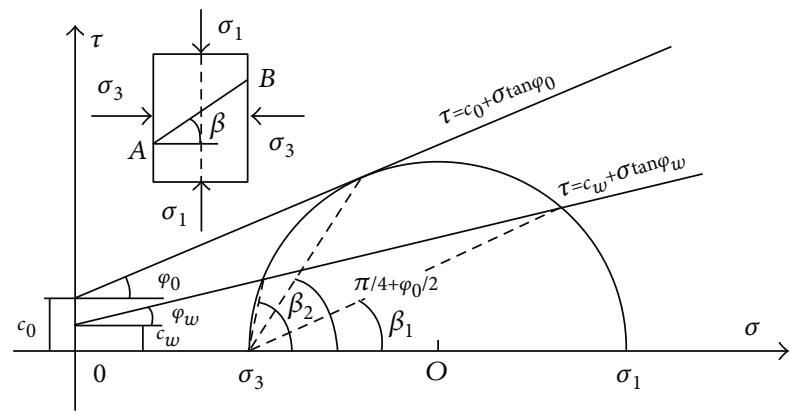

FIGURE 2: Weak plane failure curves based on the Mohr-Coulomb failure criterion. The line $\mathrm{AB}$ is defined as the weak plane. $\tau$ is the shear stress at failure.

between the bedding planes and the coring orientation. Wasantha et al. [18] studied the mechanics property of sandstone specimens with six different interconnected joint patterns under three different combinations of confining pressure and initial pore-water pressure. Liu et al. [19] found that the presence of the weak plane greatly reduced the mechanical strength of the shale. Although the above experimental methods can measure the value of the mechanical properties of the weak plane, lots of triaxial test data is necessary to fit the properties.

In this paper, an evaluation method of the mechanics parameters of weak plane bedding is proposed to improve the accuracy of weak plane bedding mechanical properties. On the other hand, a validation method of the mechanics parameters of weak plane bedding is proposed to ensure their accuracy. It is observed that the proposed evaluation and validation methods can be used to measure the value of weak plane bedding mechanical properties precisely and avoid blindness of coring operation. Rock mechanical properties of the mudstone specimen are measured using an RTR1500 triaxial rock testing system with an axial strain loading rate of $0.05 \%$ per minute under successively higher confining pressures. The frame stiffness, axial load, and cell pressure of the RTR-1500 triaxial rock testing system are $0 \mathrm{MN} / \mathrm{mm}$, Max. $1500 \mathrm{kN}$, and Max. $140 \mathrm{MPa}$, respectively. Experimental results show that the proposed evaluation and validation methods can be used to measure the value of weak plane bed-

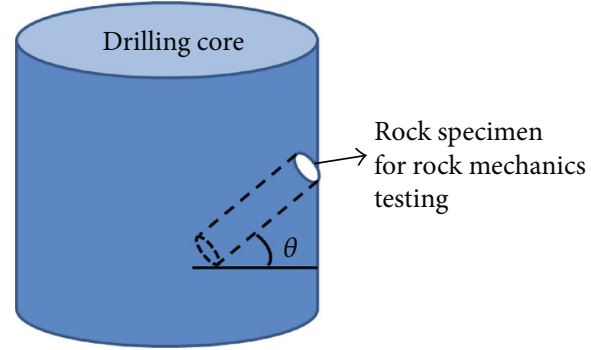

FIGURE 3: Sketch for the drilling core and rock specimen.

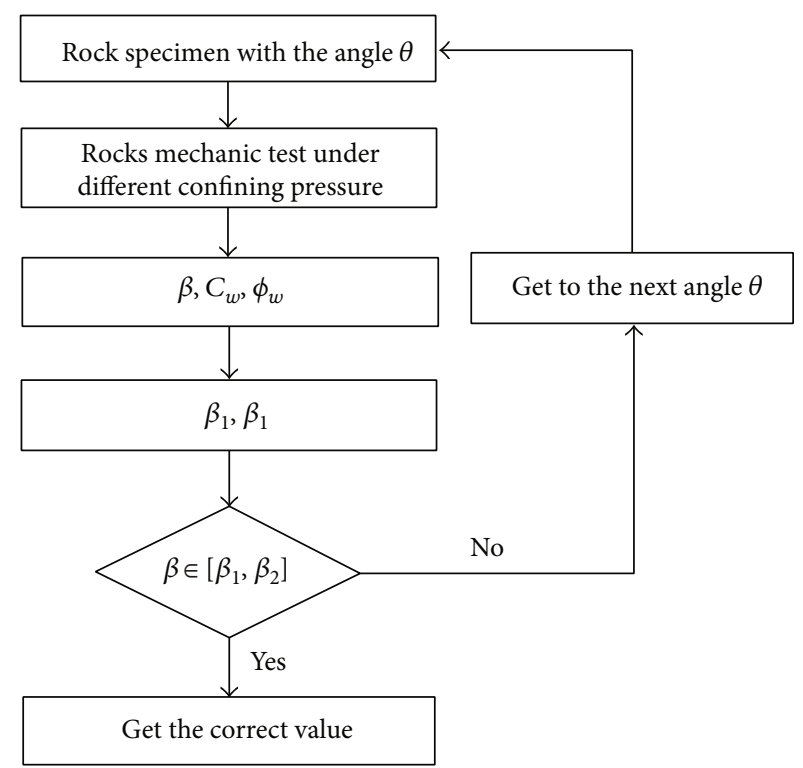

Figure 4: A flow chart for the determination of the cohesion and friction angle of the weak plane.

ding mechanical properties precisely. The proposed methods are general and can be used for measuring the mechanical properties of fracture weak-plane and joint weak-plane.

\section{Weak Plane Failure Criterion}

The weak plane failure criterion which is that the failure condition of the anisotropic mudstone depends on sets of the single weak plane parameters was the first presented by Jaeger with the most extensive triaxial tests [1]. There are an upper limit and a lower limit for the compressive strength of the anisotropic mudstone with the weak plane. The upper limit is corresponding to the compressive strength depending on the rock mass. The lower limit is corresponding to the compressive strength depending on the weak plane. $\beta$ is the angle between maximum principal stress and weak plane normal, related to the failure mode of the anisotropic mudstone with the weak plane (Figures 1 and 2). For $\beta_{1} \leq \beta \leq$ $\beta_{2}$, the failure mode is conducted by the weak plane failure.

The weak plane failure criterion for $\beta_{1} \leq \beta \leq \beta_{2}$ is defined as

$$
\sigma_{1}-\sigma_{3}=\frac{2\left(C_{w}+\tan \phi_{w} \sigma_{3}\right)}{\left(1-\tan \phi_{w} \cot \beta\right) \sin 2 \beta}
$$




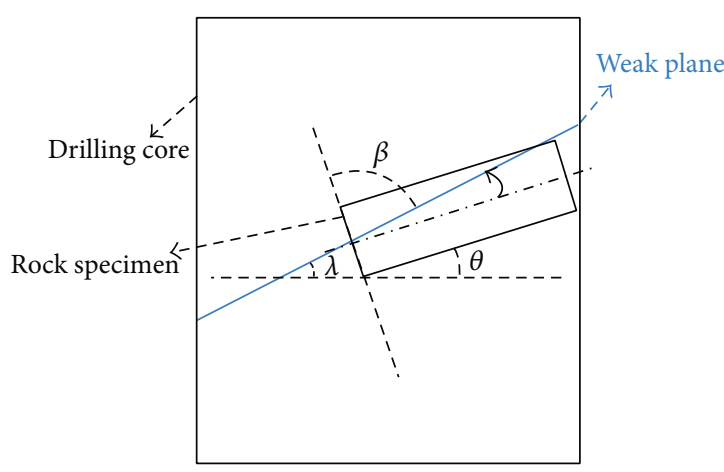

(a)

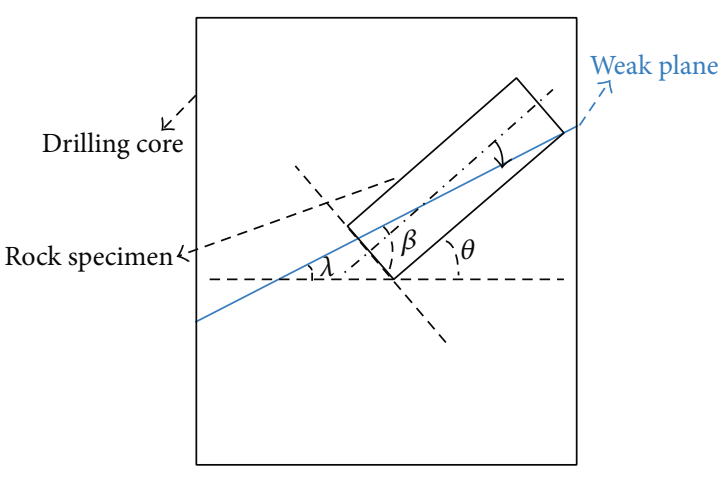

(b)

FIGURE 5: Geometric sketch for the original angle of $\lambda$. (a) The orientation from the axis of the tested rock to the weak-plane line is anticlockwise, $\theta<\lambda$. (b) The orientation from the axis of the tested rock to the weak-plane line is clockwise, $\theta>\lambda$.
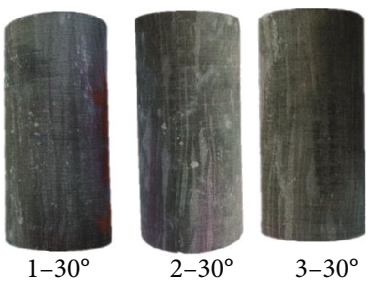

Figure 6: Standard cylinder $(\phi 25 \mathrm{~mm} \times 50 \mathrm{~mm})$.

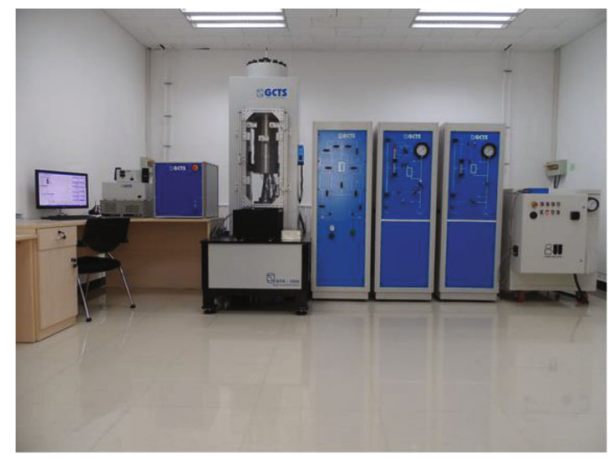

FIgURe 7: RTR-1500 Rock triaxial experiment system.

$$
\beta_{1}=\frac{\phi_{w}}{2}+\frac{1}{2} \arcsin \left[\frac{\left(\sigma_{1}+\sigma_{3}+2 C_{w} \cot \phi_{w}\right) \sin \phi_{w}}{\sigma_{1}-\sigma_{3}}\right],
$$

$$
\beta_{2}=\frac{\pi}{2}+\frac{\phi_{w}}{2}-\frac{1}{2} \arcsin \left[\frac{\left(\sigma_{1}+\sigma_{3}+2 C_{w} \cot \phi_{w}\right) \sin \phi_{w}}{\sigma_{1}-\sigma_{3}}\right],
$$

where $\sigma_{1}$ and $\sigma_{3}$ is the maximum and minimum principal stress, respectively. $C_{w}$ is the cohesion of the weak plane. $\phi_{w}$ is the friction angle of the weak plane [11].

The Mohr-Coulomb failure criterion for $\beta<\beta_{1}$ or $\beta>\beta_{2}$ is defined as

$$
\sigma_{1}=\sigma_{3} \tan ^{2}\left(\frac{\pi}{4}+\frac{\phi_{o}}{2}\right)+2 C_{o} \tan \left(\frac{\pi}{4}+\frac{\phi_{o}}{2}\right)
$$
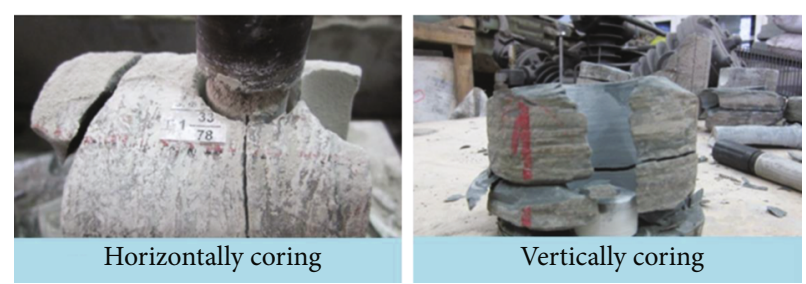

FIgURE 8: Original weak plane bedding for the drilling core.

TABLE 1: Compressive strength from triaxial test.

\begin{tabular}{lccc}
\hline $\begin{array}{l}\text { Specimen } \\
\text { number }\end{array}$ & $\begin{array}{c}\theta \\
\left(^{\circ}\right)\end{array}$ & $\begin{array}{c}\text { Confining pressure } \\
(\mathrm{MPa})\end{array}$ & $\begin{array}{c}\text { Compressive strength } \\
(\mathrm{MPa})\end{array}$ \\
\hline $1-30^{\circ}$ & 30 & 0 & 59.958 \\
$2-30^{\circ}$ & 30 & 20 & 144.852 \\
$3-30^{\circ}$ & 30 & 30 & 188.185 \\
\hline
\end{tabular}

where $C_{o}$ is the cohesion of the rock and $\phi_{o}$ is the friction angle of the rock.

\section{Evaluation Method of the Weak Plane Mechanical Properties}

$\theta$ is defined as the complementary angle of the angle between the axis of the drilling core and that of the rock specimen for rock mechanics testing (Figure 3 ). It is assumed that the angle $\beta$ of the drilling core is between $\beta_{1}$ and $\beta_{2}$. Hence, the failure mode of this rock specimen should be determined by the weak plane. The triaxial tests are run on the three rock specimens with the same $\theta$ at three different confining pressures; then, we can get three compressive strengths. The parameters $C_{w}, \phi_{w}$, and $\beta$ can be got by combining equation (1) with the three compressive strengths. $\beta_{1}$ and $\beta_{2}$ can be easily computed using equations (2) and (3). If $\beta \in\left[\beta_{1}, \beta_{2}\right]$, we will get the correct cohesion and friction angle of the weak plane, or else will increase the angle $\theta$. Figure 4 shows the algorithms with which the required cohesion and friction angle of the weak plane can be obtained. 


\section{Validation Method of the Weak Plane Mechanical Properties}

$\lambda$ is defined as the original angle which is the angle between the axis of the drilling core and weak plane normal. The original angle can be given by the geometric relationship. When the orientation from the axis of the tested rock to the weakplane line is anticlockwise, $\lambda=\theta-\beta+(\pi / 2)$ (Figure 5(a)). When the orientation from the axis of the tested rock to the weak-plane line is clockwise, $\lambda=\theta+\beta-\pi / 2$ (Figure 5(b)). We can change the angle $\theta$ to make the angle $\beta$ meet $\beta \in[$ $\left.\beta_{1}, \beta_{2}\right]$. The rock specimen with this angle $\theta$ will be conducted with a triaxial test. It can be seen from equations (2) and (3) that the failure model of the rock specimen with this angle $\theta$ will be the weak plane failure. If the value of the compressive strength from the triaxial test is close to that from the theoretic calculation of the weak plane failure criterion, the previous cohesion and friction angle of the weak plane got by the method of evaluating the weak plane mechanical properties will be accurate.

\section{Experiments and Discussions on Weak Plane Mechanical Properties}

5.1. Materials and Experimental Methodology. Mudstone samples buried to 6670-6678 m were obtained from the Sangtamu formation in Tarim Basin, Northwest China. The Tarim Basin has abundant hydrocarbons and is currently the largest natural gas-producing region in the country. The complex situations in the process of drilling are liable to occur while drilling in the Sangtamu formation in Tarim Basin. Rock mechanical properties of weak plane bedding in mudstones are of vital significance to these situations because of the poor mechanical properties of weak plane bedding. The rock specimens are from the drilling core according to the angle depicted in Figure 3. The geometry size of these rock specimens is $50 \mathrm{~mm}$ in length and $25 \mathrm{~mm}$ in diameter (Figure 6). Rock mechanics of these rock specimens are tested with an RTR-1500 triaxial rock testing system with an axial strain loading rate of $0.05 \%$ per minute under successively higher confining pressures (Figure 7).

\subsection{Experimental Results and Analysis}

5.2.1. Experiment for Evaluation Method of the Weak Plane Mechanical Properties. We can find that the original angle $\lambda$ is $10^{\circ}$ when the drilling core is coring along with the horizontal or vertical direction (Figure 8 ). We choose to conduct the triaxial test for the rock specimens with $\theta=30^{\circ}$. The compressive strength values of these rock specimens are listed in Table 1. The stress-strain curves of these rock specimens are as shown in Figure 9. By equation (1), we can obtain that $\beta=69.3697^{\circ}, c_{w}=13.0318 \mathrm{MPa}$, and $\phi_{w}=37.7435^{\circ}$. Then, $\beta_{1}$ and $\beta_{2}$ can be given by equations (2) and (3), which are listed in Table 2 . It can be easily verified that $\beta \in\left[\beta_{1}, \beta_{2}\right]$. Therefore, $c_{w}=13.0318 \mathrm{MPa}$ and $\phi_{w}=37.7435^{\circ}$ are the required cohesion and friction angle of the weak plane.

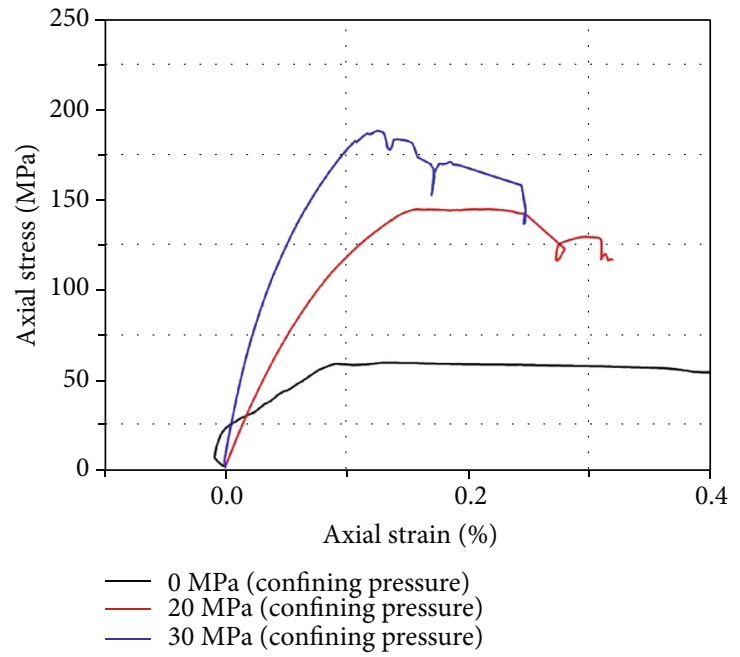

Figure 9: Stress-strain curves of rock specimens from Sangtamu mudstone formation.

TABLE 2: Relationship among $\beta, \beta_{1}$, and $\beta_{2}$.

\begin{tabular}{lccc}
\hline Specimen number & $\begin{array}{c}\beta_{1} \\
\left({ }^{\circ}\right)\end{array}$ & $\begin{array}{c}\beta_{2} \\
\left({ }^{\circ}\right)\end{array}$ & $\begin{array}{c}\beta \\
\left(^{\circ}\right)\end{array}$ \\
\hline $1-30^{\circ}$ & 55.3291 & 72.4144 & 69.3697 \\
$2-30^{\circ}$ & 57.2389 & 70.5046 & 69.3697 \\
$3-30^{\circ}$ & 57.4011 & 70.3424 & 69.3697 \\
\hline
\end{tabular}

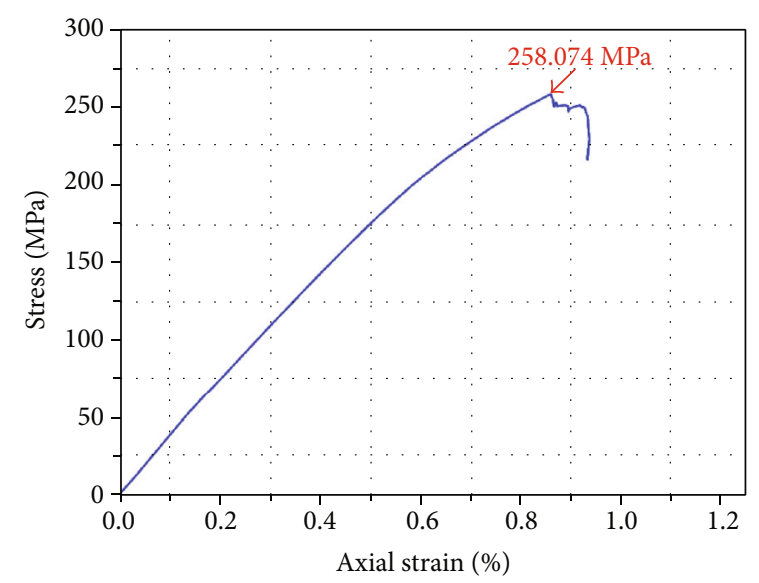

FiguRE 10: Stress-strain curves of the verified rock specimen with $\theta=35.4980^{\circ}$.

5.2.2. Experiment for Validation Method of the Weak Plane Mechanical Properties. As $\lambda=\theta+\beta-90^{\circ}$, we have $\theta=30^{\circ}$, $\beta=69.3697^{\circ}$, and so $\lambda=9.3697^{\circ}$. We should drill the rock specimen with $\theta=35.4980^{\circ}$ again, according to the validation method of the weak plane mechanical properties described in Section 4. The compressive strength of this rock specimen is measured with an RTR-1500 three-axial rock testing system for checking the difference between the experimental value of compressive strength and the calculated value of that from the weak plane failure criterion. The stress-strain curve of this rock specimen is as shown in Figure 10. The 
experimental value of compressive strength is $258.074 \mathrm{MPa}$, and the calculated value of that is $260.9528 \mathrm{MPa}$. The relative error between the results of the theoretic calculation and experiment is only $1.12 \%$. Therefore, the previously obtained weak plane mechanical properties by the evaluation method of the weak plane mechanical properties is accurate.

\section{Conclusions}

In this paper, we investigated both the evaluation method and the validation method of the weak plane mechanical properties by the theory analysis and experimental investigation in mudstone with the weak plane bedding. The evaluation method of the weak plane mechanical properties is proposed, based on the weak plane failure criterion. This method can guide the measurement of the weak plane mechanical properties to avoid blindness of coring operation. The validation method of the weak plane mechanical properties is proposed, equally based on the weak plane failure criterion. The validation method can further ensure the correctness of the weak plane mechanical properties which is previously obtained by the evaluation method of the weak plane mechanical properties. Both methods are general and can be used for measuring the mechanical properties of fracture weak-plane or joint weak-plane.

\section{Data Availability}

The manuscript is a data self-contained article, whose results were obtained from the laboratory analysis, and the entire data are presented within the article.

\section{Conflicts of Interest}

The authors declare that there is no conflict of interest regarding the publication of this paper.

\section{Acknowledgments}

This study is supported by the Open Fund of State Key Laboratory of Shale Oil and Gas Enrichment Mechanisms and Effective Development (Program No. 20-YYGZ-KF-GC15), Natural Science Basic Research Plan in Shaanxi Province of China (Program No. 2021JM-407), and National Natural Science Foundation of China (Grant No. 52004215).

\section{References}

[1] M. H. P. Bott, “The mechanics of oblique slip faulting," Geological Magazine, vol. 96, no. 2, pp. 109-117, 1959.

[2] J. C. Jaeger, "Shear failure of anistropic rocks," Geological Magazine, vol. 97, no. 1, pp. 65-72, 1960.

[3] E. Hoek, C. Carranza-Torres, and B. Corkum, "Hoek-Brown failure criterion-2002 edition," in Proceedings of NARMSTac, vol. 1, pp. 267-273, 2002.

[4] Y. Wang, Y. F. Yi, C. H. Li, and J. Q. Han, "Anisotropic fracture and energy characteristics of a Tibet marble exposed to multi-level constant-amplitude (MLCA) cyclic loads: a labscale testing," Engineering Fracture Mechanics, vol. 244, article 107550, 2021.
[5] B. S. Aadnoy, "Modeling of the stability of highly inclined boreholes in anisotropic rock formations (includes associated papers 19213 and 19886)," SPE Drilling Engineering, vol. 3, no. 3, pp. 259-268, 1988.

[6] B. S. Aadnoy and K. Larson, "Method for fracture-gradient prediction for vertical and inclined boreholes," SPE Drilling Engineering, vol. 4, no. 2, pp. 99-103, 1989.

[7] S. H. Ong and J. C. Roegiers, "Influence of anisotropies in borehole stability," International Journal of Rock Mechanics and Mining Sciences \& Geomechanics Abstracts, vol. 30, no. 7, pp. 1069-1075, 1993.

[8] T. Popp, K. Salzer, and W. Minkley, "Influence of bedding planes to EDZ-evolution and the coupled HM properties of Opalinus Clay," Physics and Chemistry of the Earth, Parts $A / B / C$, vol. 33, no. s1, pp. S374-S387, 2008.

[9] H. Lee, S. H. Ong, M. Azeemuddin, and H. Goodman, “A wellbore stability model for formations with anisotropic rock strengths," Journal of Petroleum Science \& Engineering, vol. 96-97, pp. 109-119, 2012.

[10] J. Zhang, "Borehole stability analysis accounting for anisotropies in drilling to weak bedding planes," International Journal of Rock Mechanics \& Mining Sciences, vol. 60, pp. 160-170, 2013.

[11] C. Liang, M. Chen, Y. Jin, and Y. Lu, "Wellbore stability model for shale gas reservoir considering the coupling of multiweakness planes and porous flow," Journal of Natural Gas Science and Engineering, vol. 21, pp. 364-378, 2014.

[12] Y. Wang, C. H. Li, and J. Q. Han, "On the effect of stress amplitude on fracture and energy evolution of pre-flawed granite under uniaxial increasing-amplitude fatigue loads," Engineering Fracture Mechanics, vol. 240, article 107366, 2020.

[13] W. Feng, D. Li, G. Wang, and Y. Song, "Wellbore Stability of a Deep-Water Shallow Hydrate Reservoir Based on Strain Softening Characteristics," Geofluids, pp. 1-11, 2020.

[14] F. A. Donath, "Experimental study of shear failure in anisotropic rocks," Geological Society of America Bulletin, vol. 72, no. 6, pp. 985-989, 1961.

[15] M. E. Chenevert and C. Gatlin, "Mechanical anisotropies of laminated sedimentary rocks," Society of Petroleum Engineers Journal, vol. 5, no. 1, pp. 67-77, 1965.

[16] G. Duveau and J. F. Shao, "A modified single plane of weakness theory for the failure of highly stratified rocks," International Journal of Rock Mechanics and Mining Sciences, vol. 35, no. 6, pp. 807-813, 1998.

[17] S. Heng, Y. Guo, C. Yang, J. J. Daemen, and Z. Li, "Experimental and theoretical study of the anisotropic properties of shale," International Journal of Rock Mechanics \& Mining Sciences, vol. 74, pp. 58-68, 2015.

[18] P. L. P. Wasantha, P. G. Ranjith, and D. R. Viete, "Hydromechanical behavior of sandstone with interconnected joints under undrained conditions," Engineering Geology, vol. 207, pp. 66-77, 2016.

[19] T. Liu, H. Liu, Y. Meng, X. Han, S. Cui, and A. Yu, "Multi-coupling stress field and evaluation of borehole stability in deep brittle shale," Arabian Journal of Geosciences, vol. 13, no. 21, pp. 1-9, 2020. 